\title{
Editorial
}

\section{Wechsel in der Chefredaktion der Zeitschrift Sozial- und Praventivmedizin}

Mit der jetzt vorliegendèn Numimer der s Sozial und Präventivmedizin" hat auch ein neuer Chefredaktor, nämlich Prof Dr. med. Robert Steffen, seine Tätigkeit aufgenommen, Gleichzeitg tritt Prof Dr med. Fred PaC. caud als Chefredaktor zurück, eine Funktion, die er nun seit Ende 1988 inne hatte.

Prof. Paccaud ist 1985 in dle Redaktion der Zeitschnit eingetreten. Der damaligen Chefredaktion, Prof Dr med Ursula Ackermann-Liebrich. Basel, ist er vorerst als frankophoner Redaktor" zur Seite gestanden. Umgekehrt blieb frau prof Ackermann-Liebrich def Redaktion auch nach ihrem Rücktritt als Chefredaktorin treu zusammen mit Prof. fred Epstein, Zürich, welcher dann von PD Dr Bernard Martí zurichBern. abgelöst wurde. Weitere Mitglieder der Redaktion in der Agjde Pactaud waren Prof Dr Ulrich Keil BochumiMunster als Vertreter der Deutschen Gesellschaft fur Sozialmedizin und Pravention DGSMP sowe Prof Dr: Johannes Siegrist, Maarburgibüsseldorf, als vertreter der Deutschen Gesellschaft für Medizhis he Sozjologie DGMS. In diesen fünf Jahren wurde unter der Leitung von prof. Fred Paccaud Entscheidendes geleistet. So wirde ein Begutachtungssystem fur die Manuskripte eingeführl das num fur eine anonyme Beuteriung auf. internationalem Niveau burgt Die Redaktionsarbeit wurde durch eine regelmässig stattfindende Redaktionskonferenz gestrafft eine klare redaktionelle Linie wurde formuliert zudem wurde in die technische Qualität der Zeitschrift, viel investiert Dies wurde möglich, inden der damalige verlag, welcher sich vorallemaut die eigenthiche Qruckleqund der Zeitschrift beschrankte, durch einen professionellen Herausgeber ersetzt wurde. Schliesslich liess sich die Infrastruktur der Zeitschrift selbst entscheidend verbessern frau Eaude Munlemann wbemahm das Redaktionssekretariat in Lausanne und hat durch ihre intensive Mitarbeit entscheidend zur verbesserung der zeitschrifsinternen Abläufe beigetragen.

In den letzten Jahren hat sich Zahl und Qualitat der Zeitschriften im Bereich der Gesundheitswissensehaften (Public Health weiter verbes. sert Dass unsere Zeitschrift ihre Stellung behaupten und erweitern. Konnte, ist der ausgezeichneten Arbeitvon Prof. Fred Paccaud sowie den Mitgliedern der Redaktion brw des Redaktionssekretariates zu ver danken.

In Verbindung mit diesem Dank wüschen die leserinnen und Leser sowie die beteiligten Gesellschaften dem neuen chefredaktor frof $\mathrm{D}$. med. Robert Steffen und seinem Team alles Gute für die weitere Ausgestaltung der Zeitschift.

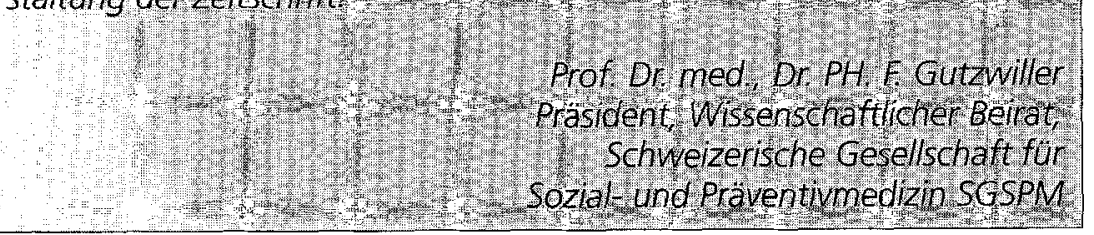

